\title{
Risk Management Assessment against the threat and disasters caused by forest fires. An application case for the Wildland Urban Interface of Valparaíso, Chile
}

\author{
Teresita de Jesús Alcántara Díaz e Sergio Mendoza Olavarría
}

\begin{abstract}
${ }^{1}$ Academic- Center of Entrepreneurs of Public Administration, Tecnológico de Monterrey México Master in Geography - Universidad de Chile.teresita.alcantara@ug.uchile.cl

${ }^{2}$ Forestal Engineer; Master of Business Administration, MBA; Risk Prevention Expert; Professor Science and Fire Management - Pontifical Catholic University of Chile. sergio.mendoza@uc.cl
\end{abstract}

\begin{abstract}
The growth of the cities has contributed to the generation of processes and dynamics linked to the transition between urban and rural-forest ecosystems, thereby enhancing the emergence of Wildland Urban Interface (WUI) spaces (Herrero-Corral, 2012), as well as problems associated with the generation of forest fires; therefore, only focusing in fostering an increase investment on emergency measures may result in more harmful and burdensome fires in the future (Mutch, Lee \& Perkins, 1998). In this sense, it is essential to have a comprehensive view on risk and its management-linked to the factors that generate conditions of vulnerability-, so the purpose of this study was to evaluate the performance of Risk Management (RM) during The 2014-2018 period, through its specific application for the city of Valparaíso, Chile and its WUI areas, taking as reference the catastrophic fire of 2014, classified as the largest urban fire in the country's history. To elaborate this evaluation, a methodological approach using indicators to obtain the Risk Management Index (RMI) considering four public policy components: risk identification, risk reduction, disaster management and governance and financial protection (risk transfer) was used. The results obtained evidenced the existence of previous risk conditions and a constant increase in vulnerability as a social construction process. In this sense, the performance level of the RM in the city in 2018 is due to an emerging or emerging adaptive response (obtaining an RMI of $\mathbf{2 . 3 1}$ over a maximum value 5), which is closely linked to the underlying factors that generate it, such as the existence and prevalence of irregular settlements and built environments not adapted to the behavior of forest fires, environmental degradation, insufficient or outdated territorial planning, and limited community capacities that do not adequately consider the DRM. Conditions which, in sum, are reflected in the limited public policies related to risk reduction and in terms of risk transfer, favoring the recurrence and increase of the effects on the city's WUI.
\end{abstract}

Keywords: WUI, RMI, risk management evaluation, public policies, land use planning. 